\title{
Activation of the \\ Liquid Helium Contamination During Its Passage in the Collider Ring
}

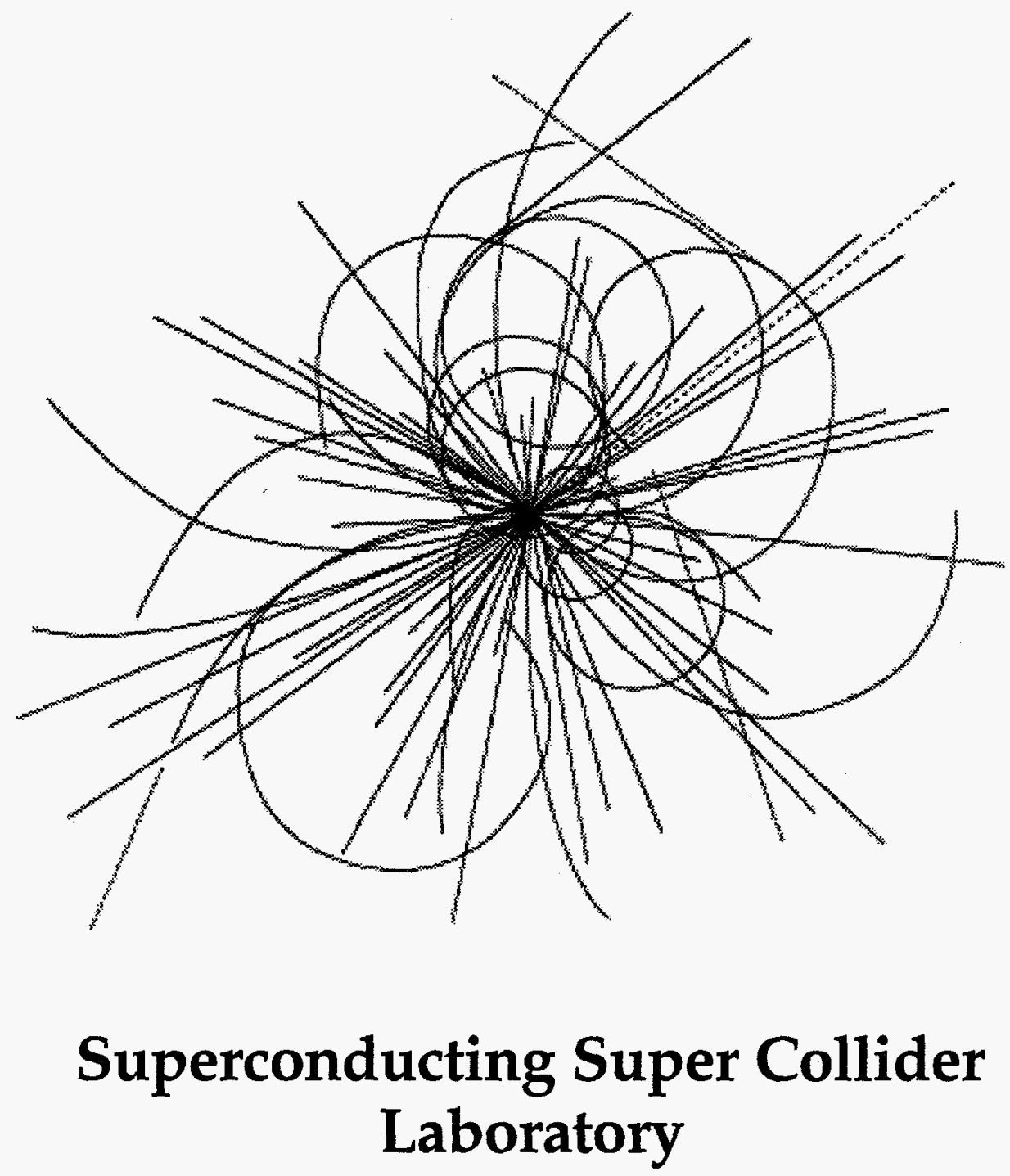

APPROVED FOR RELEASE OR

PUBLICATION - OR. PATENT GROUP

BY.. $\&$........DATE. $\%$. $\%$. 25. 


\section{Disclaimer Notice}

This report was prepared as an account of work sponsored by an agency of the United States Govemment. Neither the United States Government or any agency thereof, nor any of thei employees, makes any warranty, express or implied, or essumes any legal liability or responsibility for the accuracy, completeness, or useiulness of any information, apparatus, product, or process disclosed, or represents that its use would not infringe privately owned rights. Reference herein to any specilic commercial product, process, or service by trade name, trademark, manufacturer, or otherwise, does not necessarily constitute or imply its endorsement, recommendation, or favoring by the United States Government or any agency thereof. The views and opinions of authors expressed herein do not necessarily state or reflect those of the United States Government or any agency thereot.

Superconducting Super Collider Laboratory is an equal opportunity employer. 


\section{DISCLAIMER}

Portions of this document may be illegible in electronic image products. Images are produced from the best available original document. 


\title{
Activation of Liquid Helium Contamination During Its Passage in the Collider Ring
}

\author{
G. López \\ Superconducting Super Collider Laboratory* \\ 2550 Beckleymeade Avenue \\ Dallas, Texas 75237
}

January 1994

* Operated by the Universities Research Association, Inc., for the U.S. Department of Energy under Contract No. DE-AC35-89ER40486. 



\title{
Activation of Liquid Helium Contamination During Its Passage in the Collider Ring
}

\author{
G. López
}

\begin{abstract}
Radioactivation of possible contamination of the liquid helium trapped in the arcs of the Collider ring of the Superconducting Super Collider and transported by the liquid helium is estimated. This estimation is used to calculate the dose rate on the filter of the refrigerator plant located at the top of the shaft.
\end{abstract}




\subsection{INTRODUCTION}

The Collider ring of the Superconducting Super Collider is divided into 8.64-km sectors, with each sector connected to a refrigerator plant located at the top of the shaft. This refrigerator plant provides single-phase helium at $4.15 \mathrm{~K}$ and $3-4 \mathrm{~atm},{ }^{1}$ flowing at about $4 \times 100 \mathrm{~g} / \mathrm{s}$, to keep the temperature of the superconducting magnets in the ring at $4.35 \mathrm{~K}$. Figure 1 is a representation of the liquid helium (LHe) flow in one arc of the Collider.

During the cooldown/warm-up cycles of the Collider arcs, some type of contamination (air, $\mathrm{H}_{2} \mathrm{O}$, or $\mathrm{C}$ (from epoxies)) could be trapped in the elements of the ring (magnet coils, interconnect regions, spool pieces, pipes). This is likely to happen during the reparation of some elements in the ring. This contamination would be transported by LHe flow and captured by a highly efficient filter located at the refrigerator plant. Although the fraction of contamination to helium is thought to be small $(0.01 \%)$, there may be some concern if this contamination is radioactive. In this case, estimates of this radioactivity are required so that personnel safety can be ensured whenever the filter is changed.

\subsection{APPROACH AND CALCULATIONS}

The main source of contamination activation is the espallation products of the nuclear interaction of the contamination and high-energy secondary hadrons (mainly protons), which are produced during the beam-gas interaction during the steady state operation. The nature of these secondary particles, the energy deposited by them, and their fluence has already been studied. ${ }^{2}$ The basic analytical approach to estimating the activation of different radionuclei due to nuclear interaction is given by the following expression: ${ }^{3}$

$$
A_{k}(C i)=\frac{f_{k} \Upsilon_{k} p_{k}}{t_{i} 37 \times 10^{9}} \exp \left(-t_{d} / t_{k}\right)\left[1-\exp \left(-t_{i} / t_{k}\right)\right]
$$

with some modified factors, and where $F_{k}$ is the fraction of contamination in LHe, $p_{k}$ is the production factor per proton lost, $t_{i}$ is the irradiation time, which is given in terms of the irradiation length, $L=2 \times 8.64 \mathrm{~km}$, and LHe velocity, $V_{H e}$, as

$$
t_{i}=L / V_{H e}
$$

$t_{d}$ is the cooling time (time where there is not radiation), which is given in terms of the shaft depth, $L_{s}=60 \mathrm{~m}$, and the LHe velocity as

$$
t_{d}=L_{s} / V_{H e},
$$

$\Upsilon_{k}$ is the total number of hadrons lost, which is given in terms of the loss rate, $I=$ $10^{4} \mathrm{p} / \mathrm{m} / \mathrm{s}$, irradiation length and irradiation time as

$$
\Upsilon_{k}=t_{i} I L
$$


The concentration at the top of the shaft is estimated by

$$
C_{k}(\mu C i / m l)=\frac{10^{6} A_{k}}{t_{i} V_{H e} a_{t}},
$$

where $a_{t}$ represents the cross-sectional area where the LHe flows.

Cross-sectional sketches of the superconducting main dipole and quadrupole magnetcold-masses are shown in Figure 2. The cooling passages (channels) carry most of the $\mathrm{LHe}$, and about $10 \%$ of LHe flows through the coil-collar region. (Cross-flow cooling is not assumed at this moment.) These two different flows are mixed at the end of the magnets in the interconnect region, as shown in Figure 3. The first assumptions are that there is not mixing at the end of the magnets and that the contamination in the LHe is made of air, $\mathrm{C}$, and $\mathrm{H}_{2} \mathrm{O}$. Therefore, knowing the type of isotope and its production fraction ${ }^{4}$ (production cross section), Figures $4(\mathrm{a}), 4(\mathrm{~b})$, and 4(c) show the isotope concentration at the top of the shaft as a function of the fraction of contamination in the LHe (the estimated fraction for the Collider is 0.0001 ) for air, $\mathrm{C}$, and $\mathrm{H}_{2} \mathrm{O}$. In addition, these figures also show the fraction (in percentage) of the given isotope in the sample. This percentage does not change, of course, with the fraction of contamination in the LHe. The radioactivity in the air-contamination is dominated by the isotopes $\mathrm{N}_{13}, \mathrm{C}_{11}, \mathrm{O}_{15}, \mathrm{Ar}_{41}$, and $\mathrm{Be}_{7}$. In C-contamination, the dominant isotopes are $\mathrm{Be}_{7}$ and $\mathrm{H}_{3}$. Finally, the isotopes $\mathrm{O}_{15}, \mathrm{C}_{11}$, $\mathrm{N}_{13}$, and $\mathrm{Be}_{7}$ dominate the radioactivity of $\mathrm{H}_{2} \mathrm{O}$-contamination. The mean life, the main particle emitted, and the energy of this emitted particle (for beta decay this means the maximum energy) of these radioisotopes ${ }^{5}$ are shown in Figure 5. This set of figures shows that the radioactivation of $\mathrm{H}_{2} \mathrm{O}$ is much more important than the other type of contamination. Therefore, the short-lived isotope $\mathrm{O}_{15}$ dominates the radionuclei production.

Figures 6(a), 6(b), and 6(c) show, for a contamination-LHe fraction of $0.01 \%$, the isotope concentration at the top of the shaft as a function of the mixture-fraction of LHe at the end of the magnets (in the interconnect region). The ideal cross-flow cooling scheme for the superconducting magnets would be represented by the fraction equal to one. As expected, there is an increase in radioactivity due to this mixing, and the activity is again dominated by the $\mathrm{H}_{2} \mathrm{O}$-contamination.

Now, keeping the fraction of LHe in the coil-collar region constant (10\%), Figures 7(a), $7(\mathrm{~b})$, and 7 (c) show the isotope concentration at the top of the shaft as a function of the LHe flow rate. (The nominal value is $100 \mathrm{~g} / \mathrm{s}$ in the cooling channels.) The activation on the air- and C-contamination decreases, but the activation on the $\mathrm{H}_{2} \mathrm{O}$-contamination increases. The reason can be seen in Figure 8, where the percentage of the main isotopes in $\mathrm{H}_{2} \mathrm{O}$ is plotted as a function of the LHe flow rate. The amount of the long-lived isotope 
$\mathrm{Be}_{7}$ decreases, while the amount of the short-lived isotope $\mathrm{O}_{15}$ increases. Therefore, the total activity must increase. On the other hand, since the helium velocity $V_{H e}$ depends on its density $\left(V_{H e}=\right.$ flow-rate/He-density/area) which, in turns, depends on the pressure, one might think that there could be strong changes if the pressure changes. However, as Figure 9 shows, the density does not change strongly with the pressure around 4 atm. Therefore, the activity does not depend strongly on the pressure around the nominal value 3-4 atm.

In the above calculations, the number of particles lost per meter per second was fixed at $10^{4} \mathrm{p} / \mathrm{m} / \mathrm{s}$. This represents a simplification of the problem, since one expects to have high energy-high flux $\left(2 \mathrm{TeV}-10^{5} \mathrm{~h} / \mathrm{cm}^{2}\right)$ in the inner coil region of the magnets $(r=2.5-3 \mathrm{~cm})$ and low energy-low flux $\left(0.2 \mathrm{TeV}-7 \times 10^{3} \mathrm{~h} / \mathrm{cm}^{2}\right)$ in the iron yoke-cooling channels region $(r=15 \mathrm{~cm}) \cdot{ }^{1,6}$ In other words, the contamination flowing with the LHe in the inner coil region may be more radioactive than the contamination outside this region because the number of nuclear interactions (number of stars) can be higher in the inner coil region. The density of stars, for pure elements at different energies and at different locations, is shown in Table 1.

Table 1. Density of stars $\left(s_{i}^{*}=\phi / \lambda_{i}\right)^{a}$.

\begin{tabular}{|c|c|c|}
\hline $\begin{array}{c}r=2.5-3 \mathrm{~cm} \\
\phi=1.1 \times 10^{5} \mathrm{~h} / \mathrm{cm}^{2}\end{array}$ & $2 \mathrm{TeV}$ & $0.2 \mathrm{TeV}$ \\
\hline $\mathrm{H}_{2} \mathrm{O}$ & 1406.65 & 1297.17 \\
$\mathrm{He}$ & 201.60 & 185.36 \\
$\mathrm{C}$ & 3143.75 & 2915.36 \\
\hline$r=15 \mathrm{~cm}$ & & \\
$\phi=7 \times 10^{3} \mathrm{~h} / \mathrm{cm}^{2}$ & & \\
\hline $\mathrm{H}_{2} \mathrm{O}$ & 89.51 & 82.55 \\
$\mathrm{He}$ & 12.83 & 11.79 \\
$\mathrm{C}$ & 200.05 & 185.52 \\
\hline
\end{tabular}

${ }^{a} \lambda_{i}$ represents the radiation length.

This point is a little bit subtle, since if one considers the total radiation length $\left(\lambda^{-1}=\sum_{i} \alpha_{i} \lambda_{i}^{-1}, \alpha_{i}:\right.$ fraction of the $i$ th-component), this one would be fully dominated by the helium-hadron interaction because the contamination is less than three orders of magnitude smaller. Therefore, the average value assumed of 120 stars per hadron in the above calculations seems reasonable. Moreover, Figure 10 shows the variation of the isotope concentration in the $\mathrm{H}_{2} \mathrm{O}$ contamination as a function of the number of stars per 
hadron. The LHe flow rate in the cooling channels was taken as $100 \mathrm{~g} / \mathrm{s}$, and the fraction of contamination-LHe was $0.05 \%$. One can see that for a very large number of stars per hadron (higher than 1000), the isotope concentration can change to higher values (one order of magnitude higher). However, this may be unrealistic since the nuclear interactions are dominated by $\mathrm{LHe}$, as mentioned before.

Finally, as shown in Figure 1, the shaft depth was always kept constant $(60 \mathrm{~m})$ in the above calculations, i.e., the radioactivation cooling time $t_{d}$ was constant. Actually, the shaft depths vary from sector to sector in the Collider ring. However, one does not expect a major effect in the activity at the top of the shafts due to these variations. Figure 11 shows the total activation in the $\mathrm{H}_{2} \mathrm{O}$ contamination as a function of the shaft depth.

\subsection{DOSE ESTIMATION}

As mentioned above, a filter located at the refrigerator plant collects the contamination carried out by the LHe flow. A sketch of this cylindrical filter ${ }^{7}$ is shown in Figure 12(a). However, for practical calculations, the model shown in Figure 12(b) will be used. Although the contamination is trapped at the boundary of region II of the filter, it will be assumed that there is a uniform distribution of contamination in region I caused by the continuous flow of helium in this area. That is, in this area there is a uniform distribution of radioactivity. Under this assumption, analysis of the dose rate at boundaries I and II is simplified. This dose rate is given by

$$
\dot{D}_{k j o}=\frac{n_{j} E_{j} A_{k}}{M},
$$

where $A_{k}$ represents the activity of the $k$ th-isotope, $n_{j}$ is the multiplicity of the $i$ th-emitted particle, $E_{j}$ is the energy carried out by this emitted particle, and $M$ is the mass of the body where this energy is deposited. Clearly, the dose rate at a distance $d$ from the body varies inversely proportional to the square of this distance $\left(\dot{D}_{k j} \sim \dot{D}_{k j o} / d^{2}\right)$. As was pointed out in Section 2.0, radioactivity in the contamination-LHe is totally dominated by the activation in the $\mathrm{H}_{2} \mathrm{O}$-contamination. Therefore, only the dose rate due to the activation of $\mathrm{H}_{2} \mathrm{O}$-contamination will be considered.

Using Figures 11 and 12(b), the following data are obtained:

Total Activity $\mathrm{A}=1.02 \mu \mathrm{Ci}$,

$M_{I}=4378 \mathrm{~g}$,

and

$M_{I I}=23430 \mathrm{~g}$. 
Using these data, Figures 11 and $5\left(\beta^{+}\right.$emitters can be seen as $2 \gamma-0.511 \mathrm{MeV}$ emitters due to $\beta^{+}$annihilation), the conversion factors $1 \mathrm{rad}=6.24 \times 10^{7} \mathrm{MeV} / \mathrm{g}$ and $1 \mathrm{Ci}=$ $2.22 \times 10^{22} \mathrm{dis} / \mathrm{min}$, and Eq. (4), the following dose rates (Table 2) are obtained:

Table 2. Dose rates $\left(\dot{D}_{\circ}[\mathrm{mrad} / \mathrm{h}]\right)$.

\begin{tabular}{|c|c|c|}
\hline $\mathrm{H}_{2}$ O-contamination & Boundary I & Boundary II \\
\hline $\mathrm{H}_{3}$ & $1.08 \times 10^{-5}$ & $5.78 \times 10^{-5}$ \\
$\mathrm{Be}_{7}$ & $5.25 \times 10^{-3}$ & $2.81 \times 10^{-2}$ \\
$\mathrm{C}_{11}$ & $2.45 \times 10^{-2}$ & 0.131 \\
$\mathrm{~N}_{13}$ & $1.43 \times 10^{-2}$ & $7.65 \times 10^{-2}$ \\
$\mathrm{O}_{15}$ & $7.55 \times 10^{-2}$ & 0.404 \\
\hline
\end{tabular}

The dose rate shown above is clearly higher than the recommended dose rate, ${ }^{8}$ $0.01 \mathrm{~Sv} / \mathrm{yr}=0.114 \mathrm{mrad} / \mathrm{h}$, for humans. Therefore, a careful design and remote handling device are recommended to handle this filter.

\subsection{CONCLUSION}

Assuming that a small amount of contamination is trapped in the cold mass of the Collider ring, its radioactivation and dose rate induced on the refrigerator plant filter are estimated. This dose rate may be much higher than the recommended dose rate limit for humans, requiring a careful design for this filter. 



\section{ACKNOWLEDGEMENTS}

I wish to thank Dr. Jeff Bull and Dr. N. Mokhov for their valuable discussions and their help in this study. 



\section{REFERENCES}

1. "Site-Specific Conceptual Design," SSCL-SR-1056, July 1990.

2. I.S. Baishev, A.J. Drozhdin, and N.V. Mokhov, "Beam Loss and Radiation Effects in the SSC Lattice Elements," SSCL-306, Nov. 1990. N.V. Mokhov, "Radiation Environment/Impacts," PDRR, May 1992.

3. M. Barbier, Induced Radioactivity, North-Holland Publishing, 1969.

4. A. H. Sullivan, "Some Ideas on Radioactivity Induced in High-Energy Particle Accelerators," TIS-RP/TM/83-27, May 16, 1983.

5. C. M. Lederer and V. S. Shirley, Table of Isotopes, 7th edition, John Wiley and Sons, Inc., 1978.

6. N. V. Mokhov, personal communication.

7. S. Abramovich and R. Ganni, personal communication.

8. Annals of the ICRP, Vol. 21, No. 1-3. 1990 Recommendations of the International Commission on Radiological Protection, Pergamon Press, 1991. 



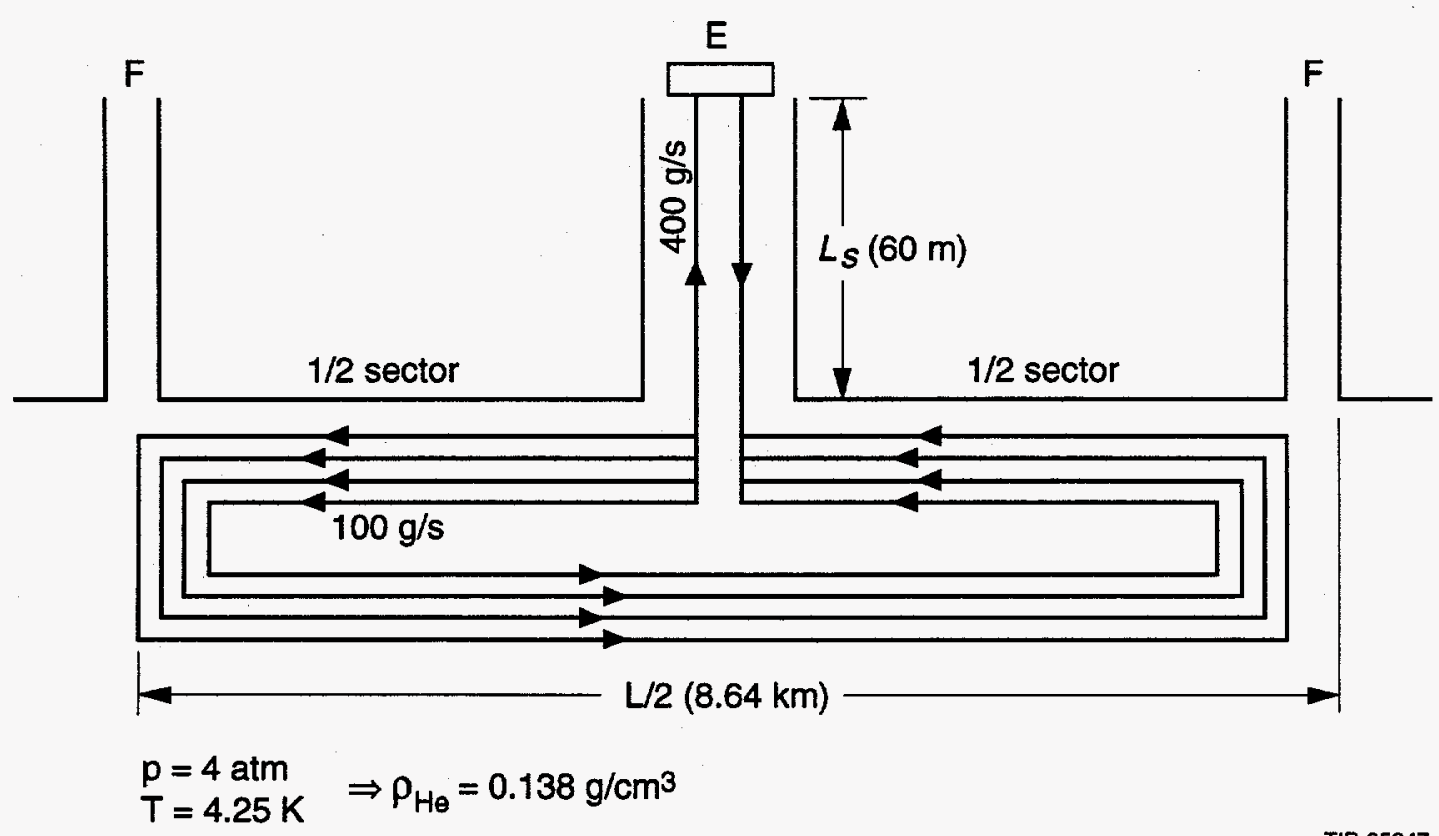

Figure 1. Model for the LHe flow. 


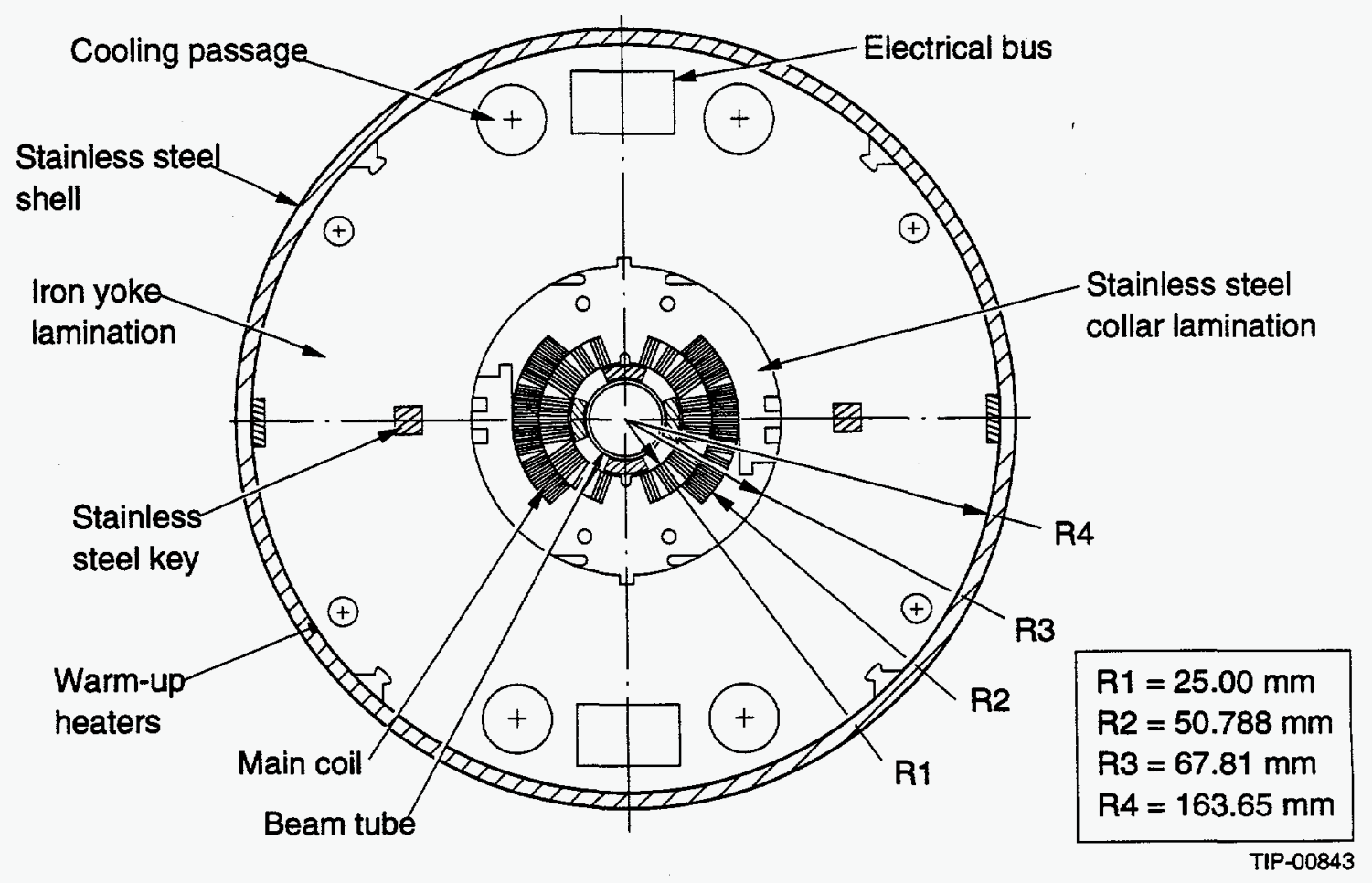

Figure 2(a). Collider dipole magnet.

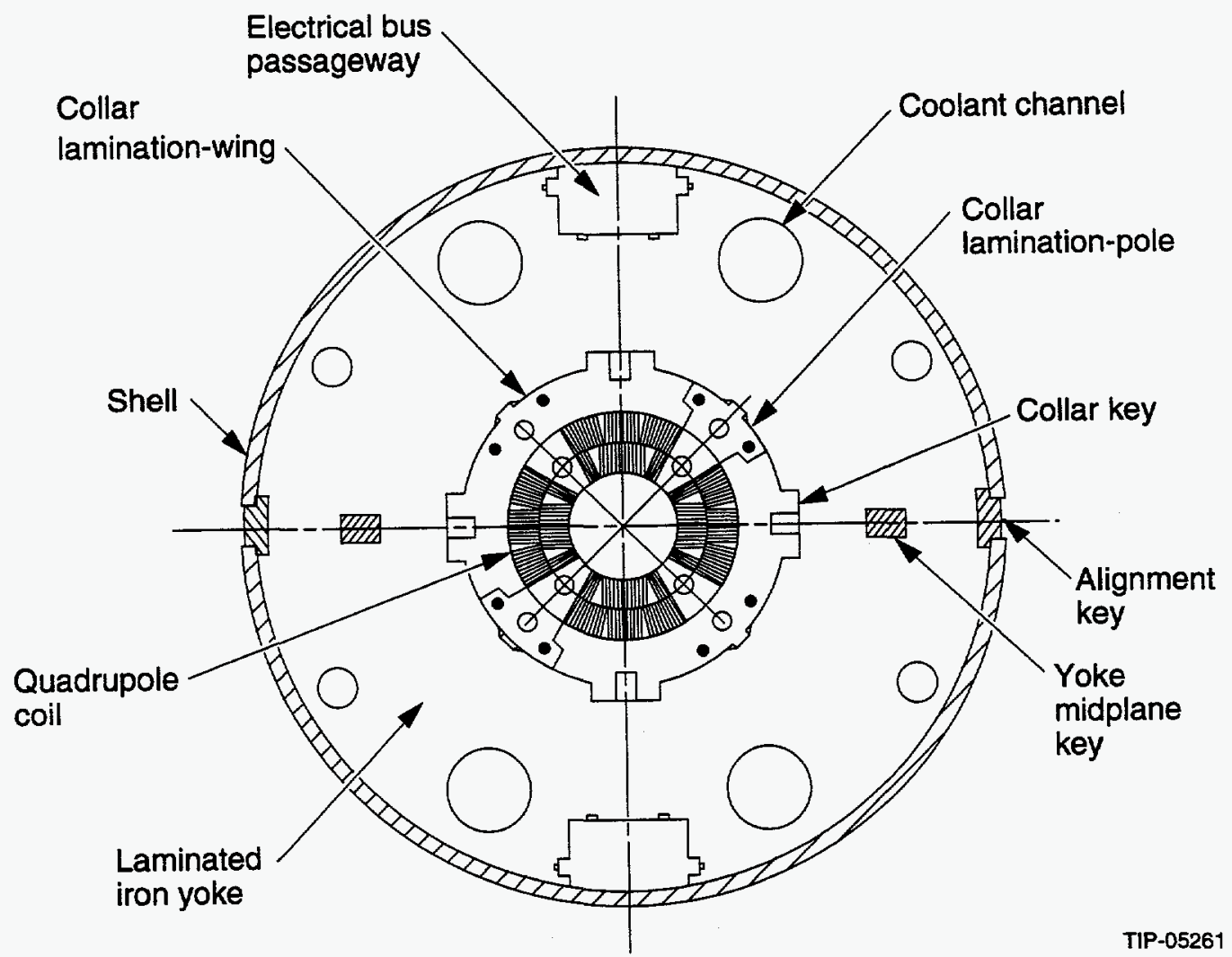

Figure 2(b). Collider quadrupole magnet. 


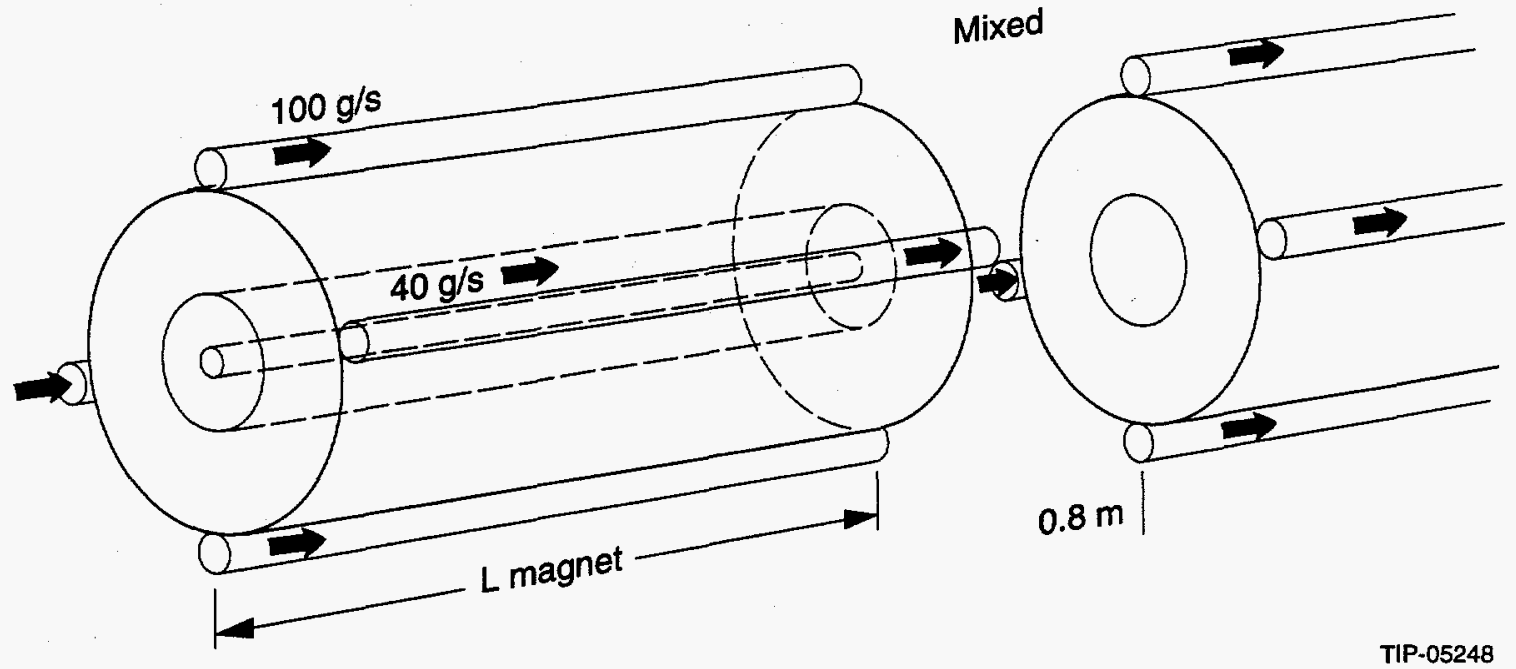

Figure 3. Mixing of LHe flows. 


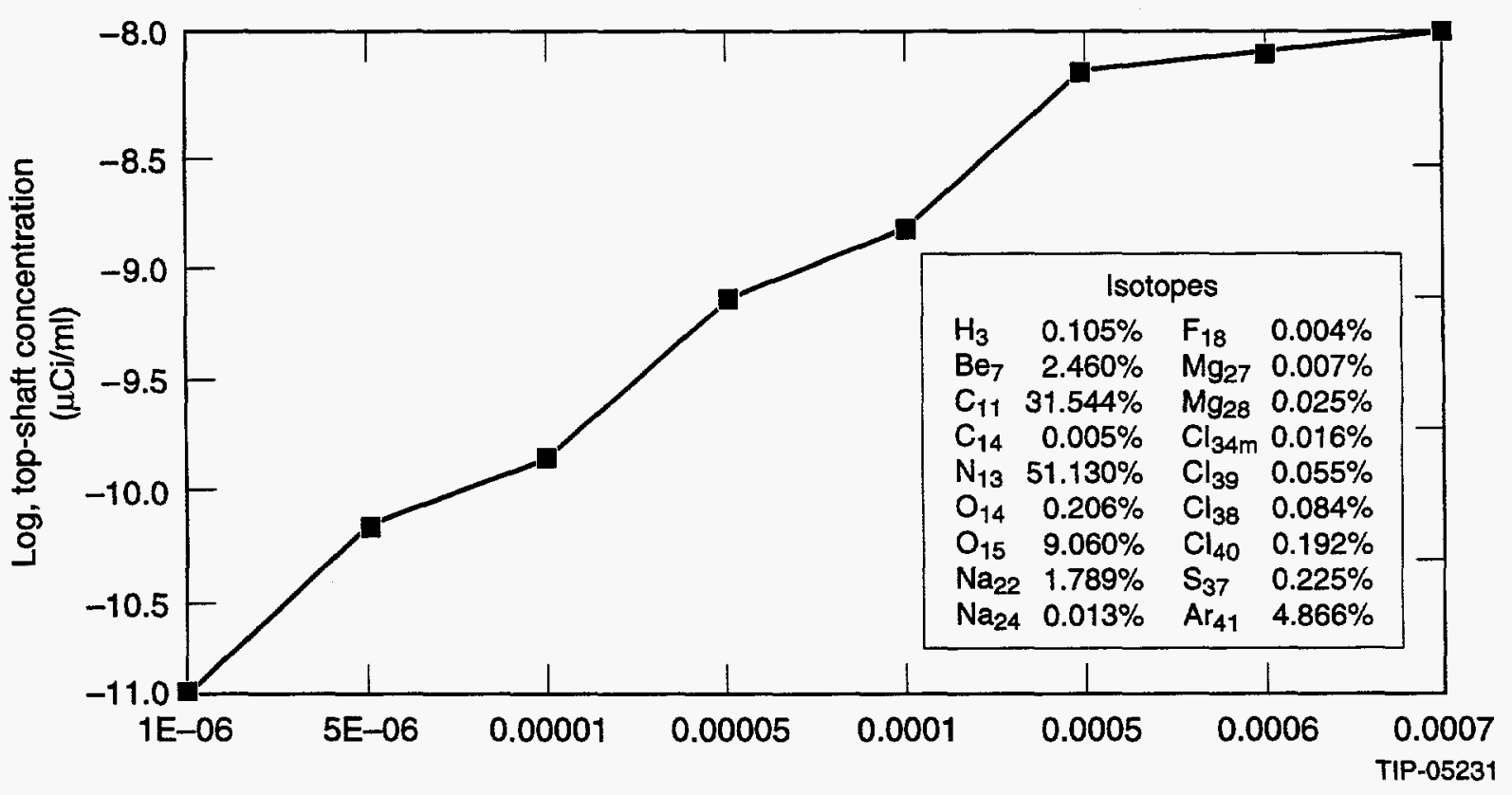

Figure 4(a). Fraction of contamination in LHe (air).

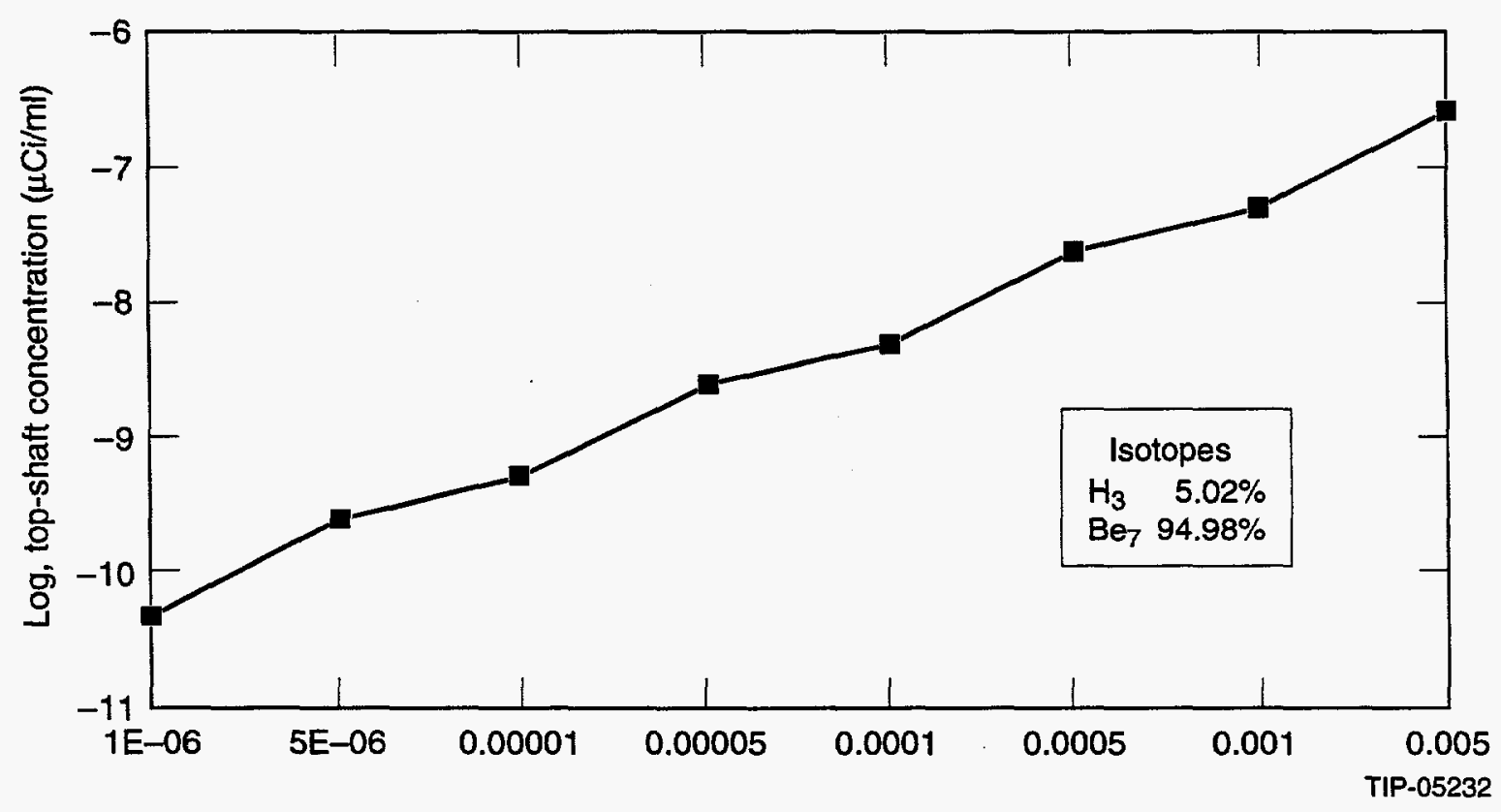

Figure 4(b). Fraction of contamination in $\mathrm{LHe}(\mathrm{C})$. 


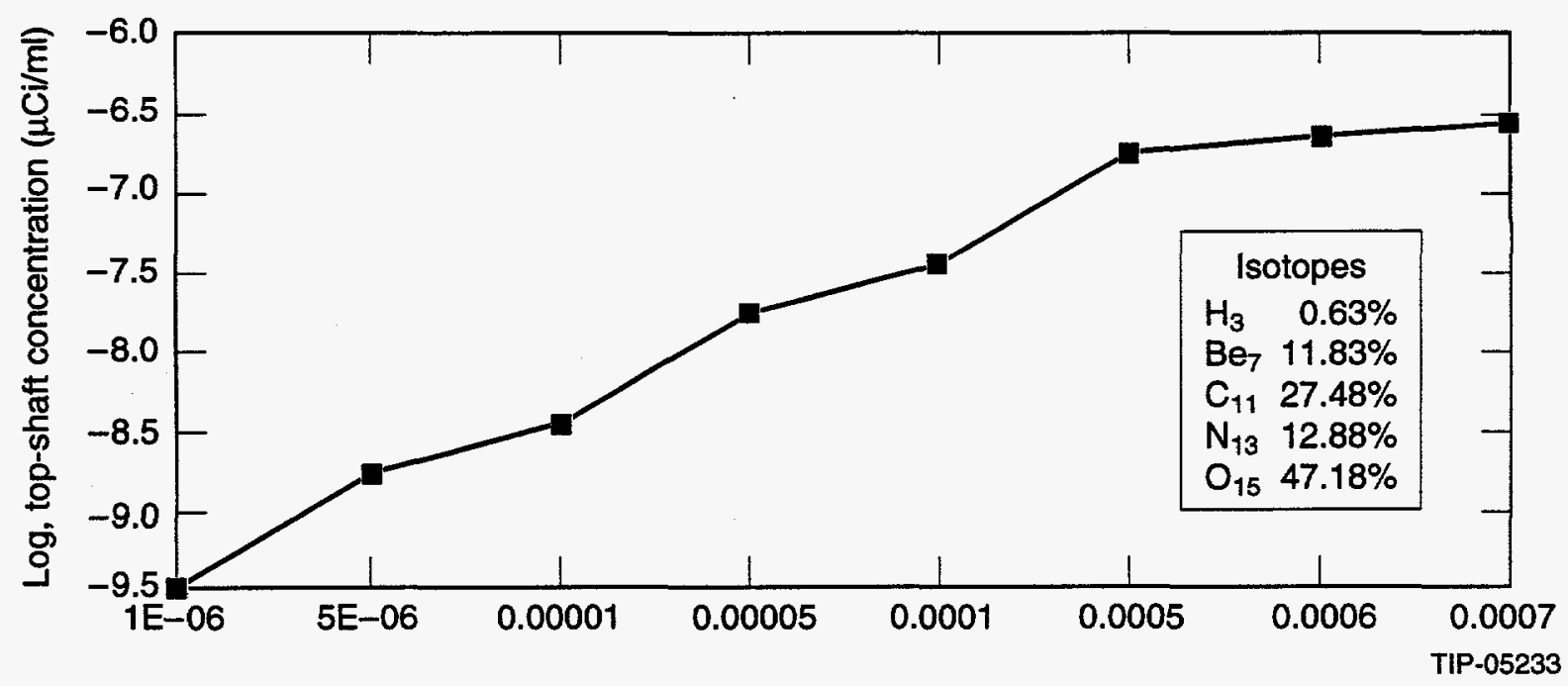

Figure 4(c). Fraction of contamination in $\mathrm{LHe}\left(\mathrm{H}_{2} \mathrm{O}\right)$.

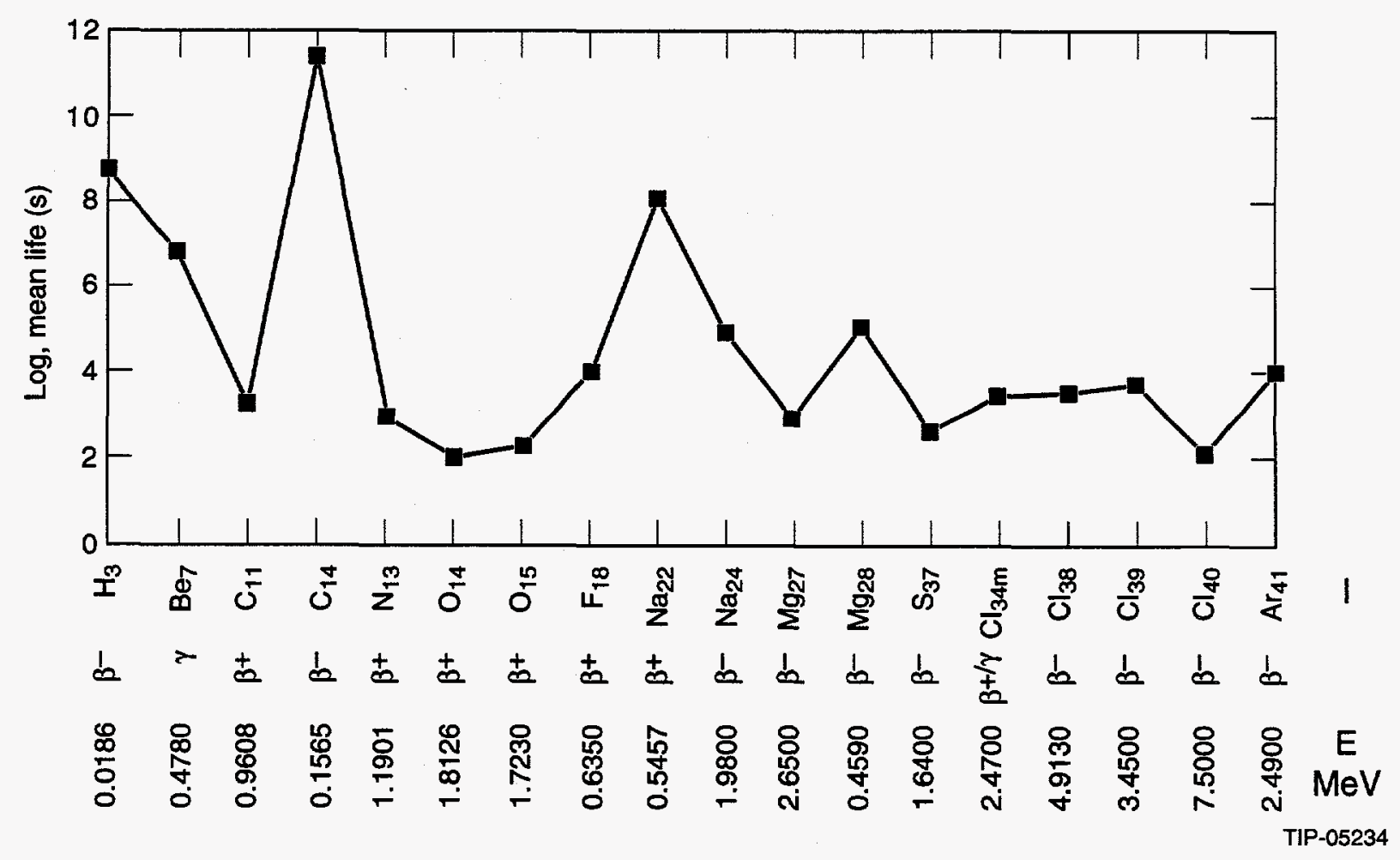

Figure 5. Properties of isotopes. 


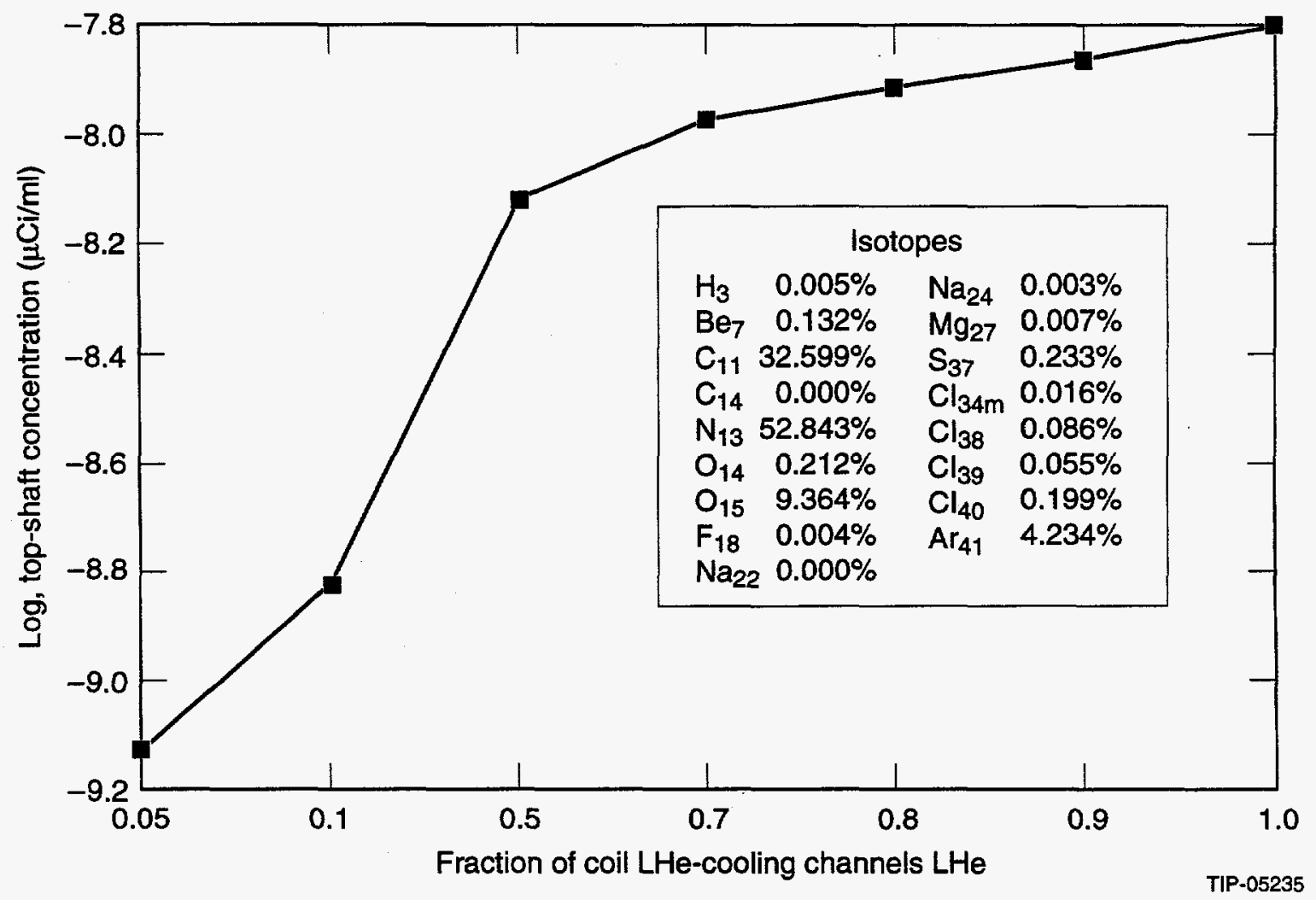

Figure 6(a). Mixture-fraction of LHe (air).

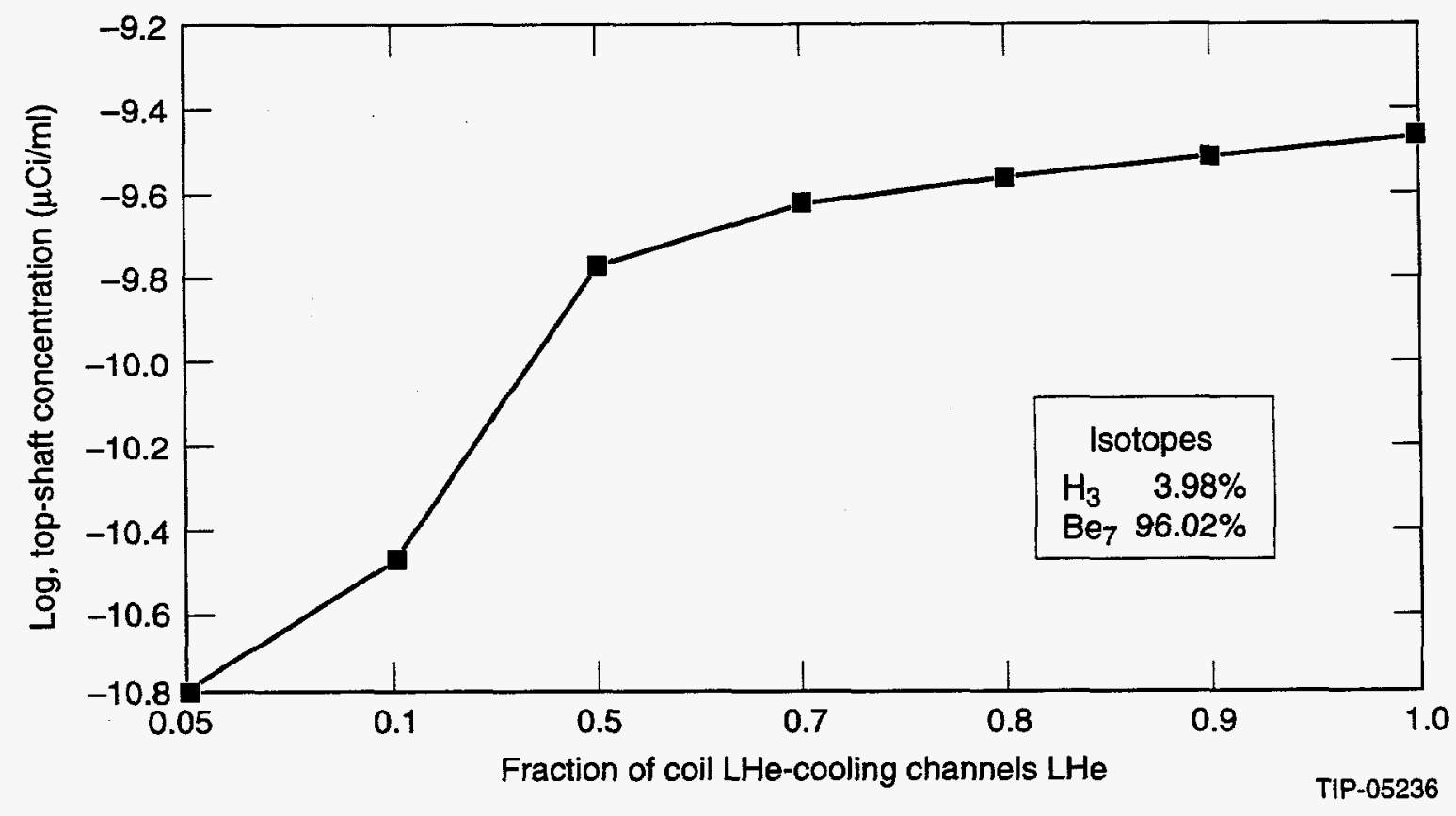

Figure 6(b). Mixture-fraction of $\mathrm{LHe}(\mathrm{C})$. 


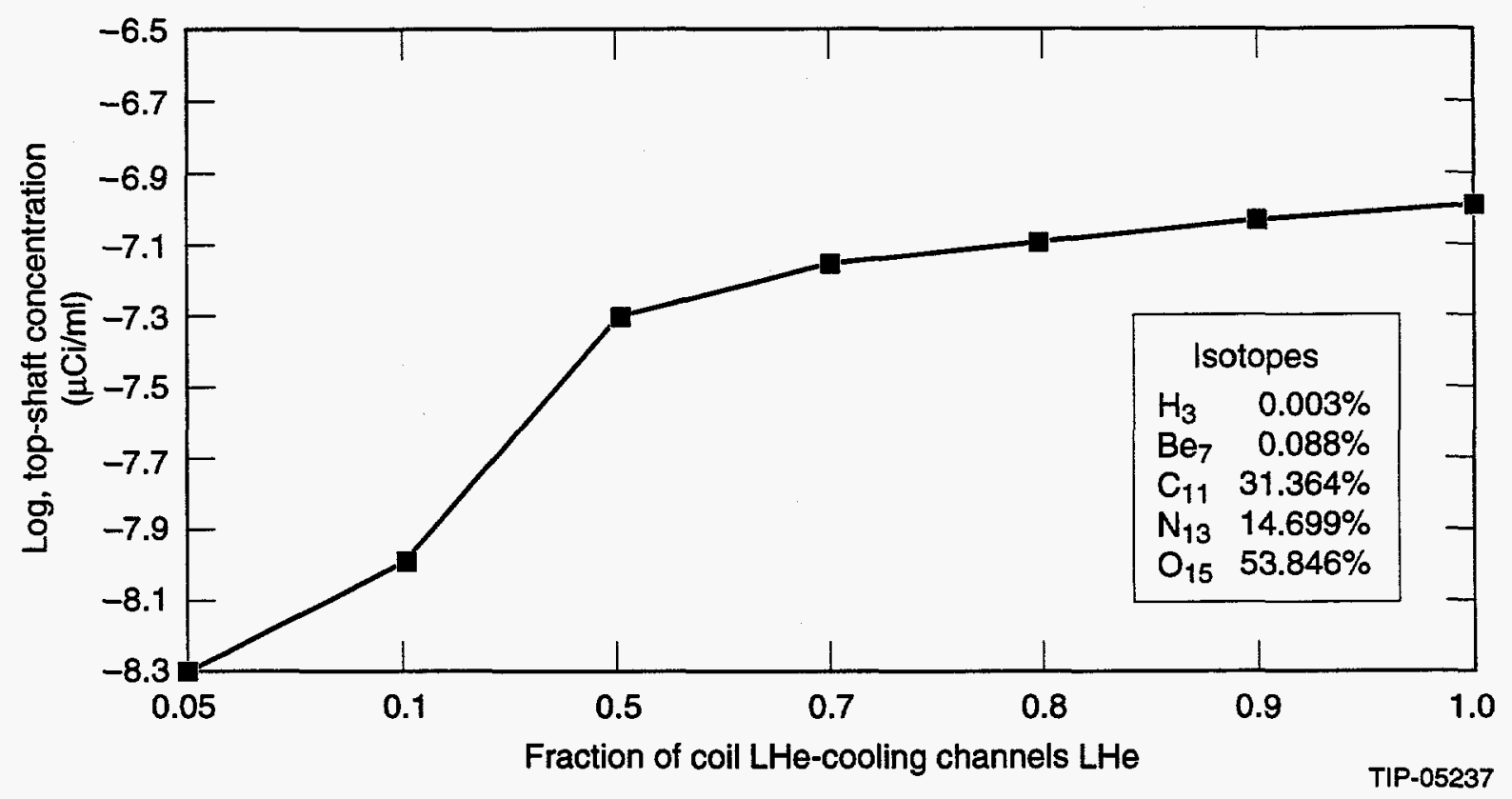

Figure 6(c). Mixture-fraction of $\mathrm{LHe}\left(\mathrm{H}_{2} \mathrm{O}\right)$.

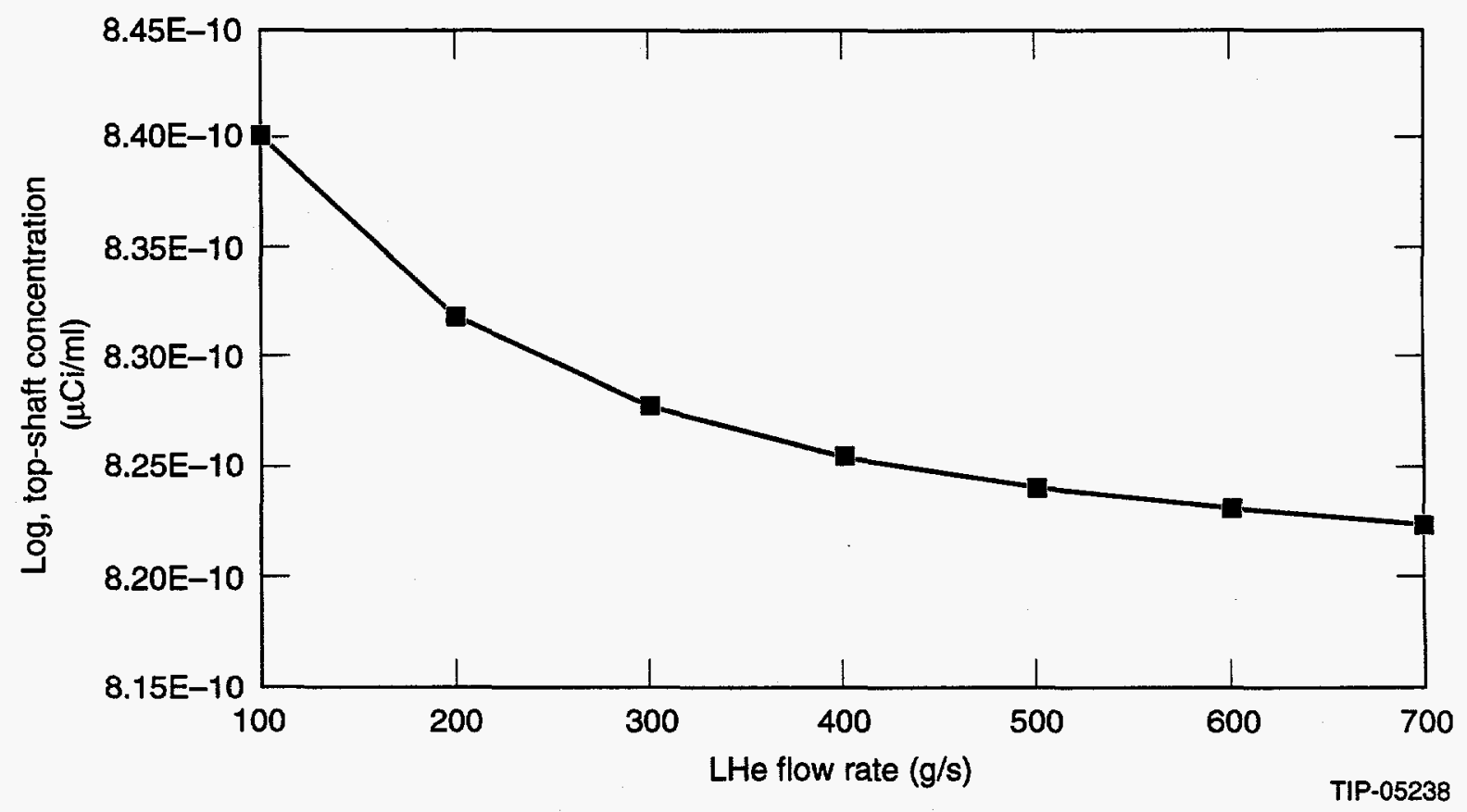

Figure 7(a). LHE flow rate (air). 


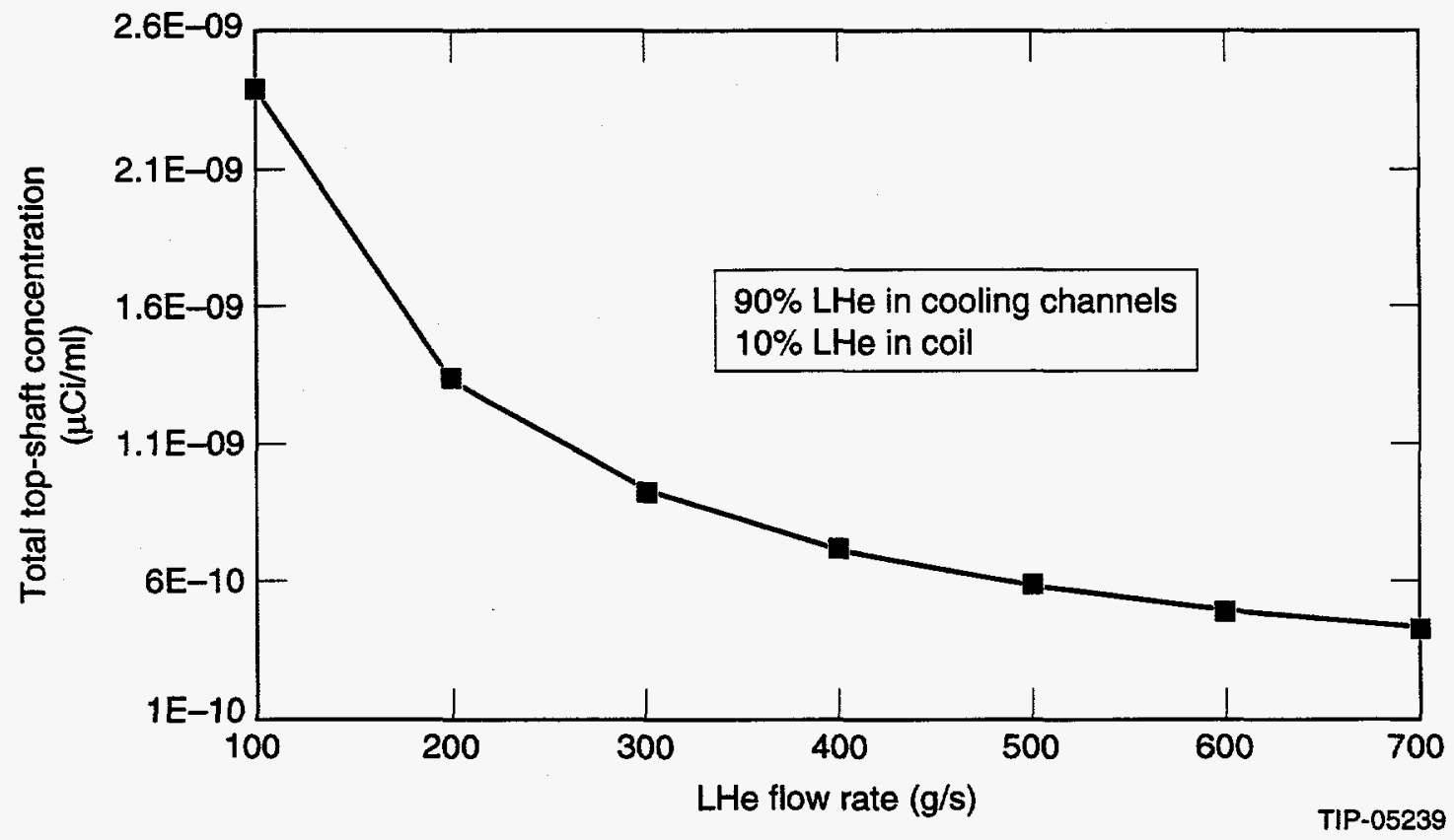

Figure $7(\mathrm{~b})$. LHE flow rate (C).

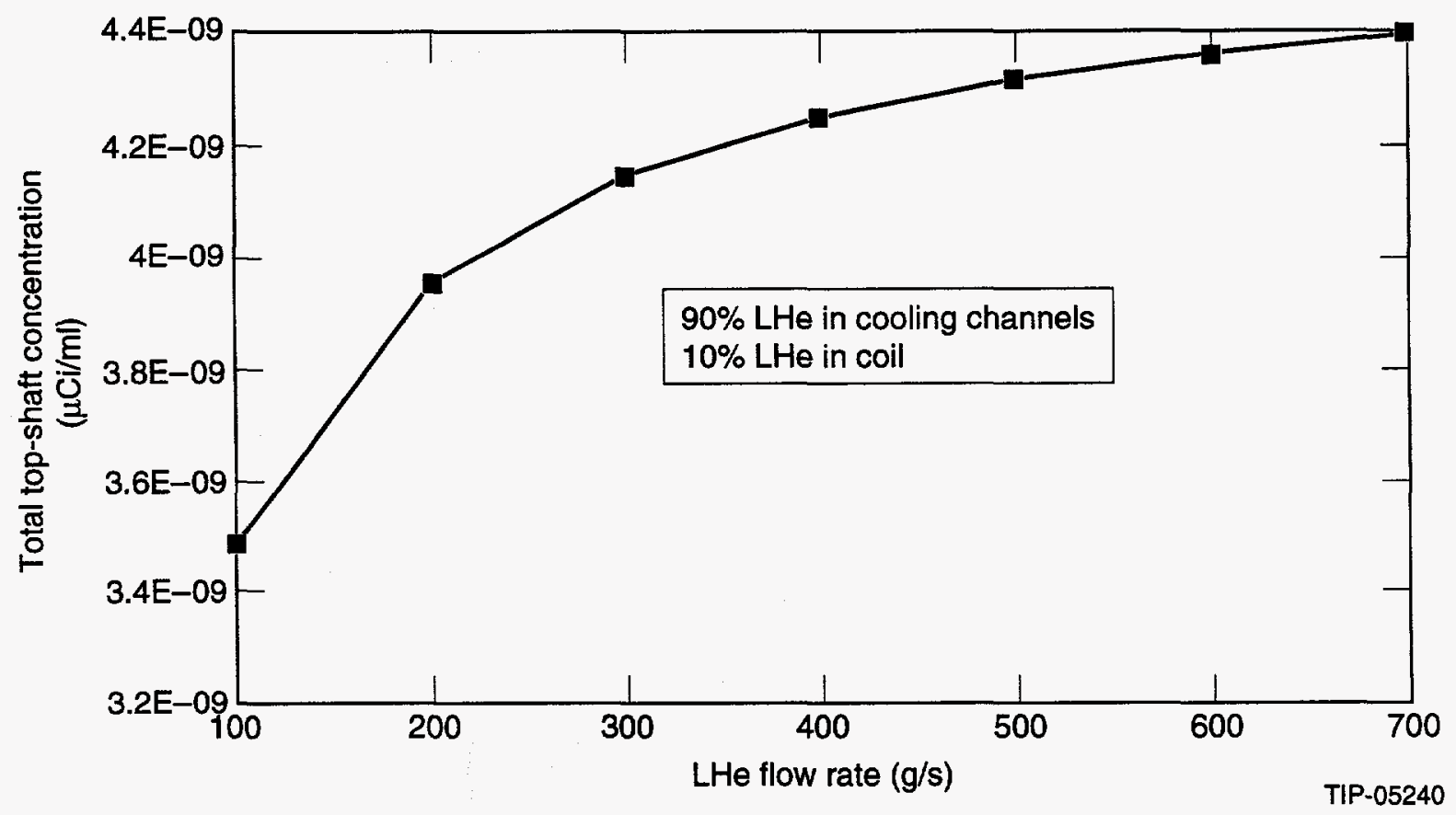

Figure $7(\mathrm{c})$. LHE flow rate $\left(\mathrm{H}_{2} \mathrm{O}\right)$. 


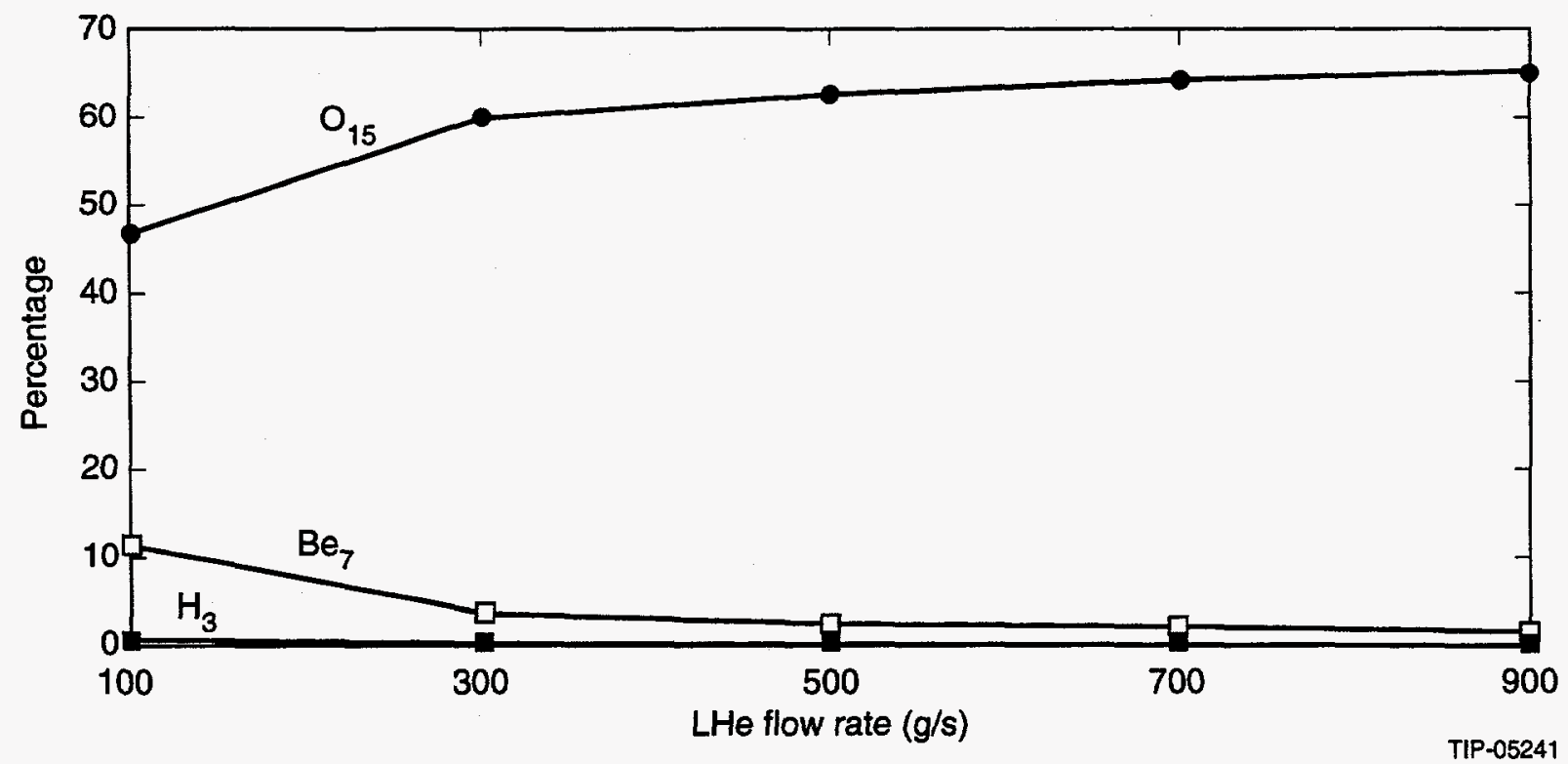

Figure 8. Percentage of the main isotopes in $\mathrm{H}_{2} \mathrm{O}$ as a function of $\mathrm{LHe}$ flow rate.

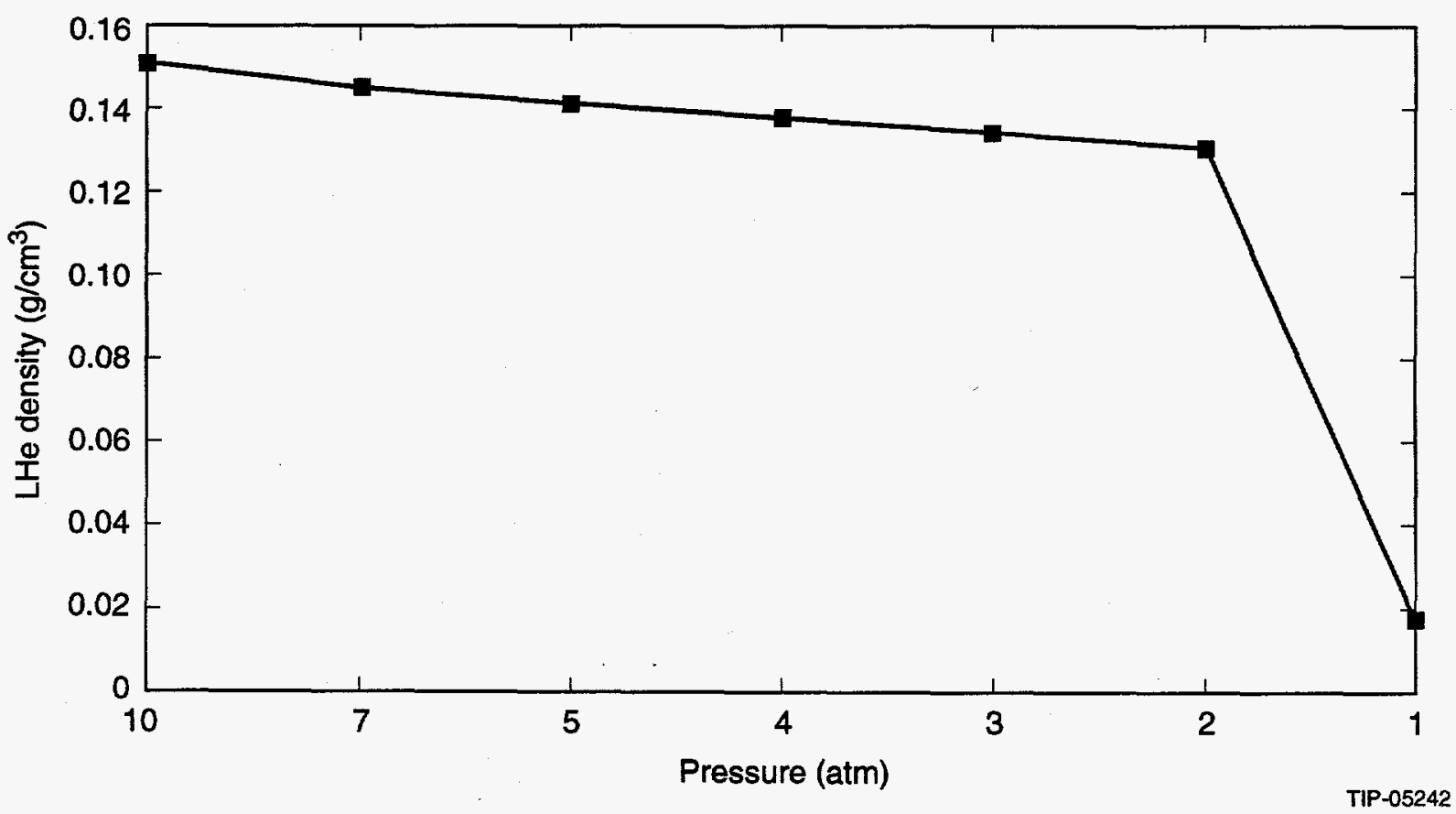

Figure 9. LHe density vs. pressure. 


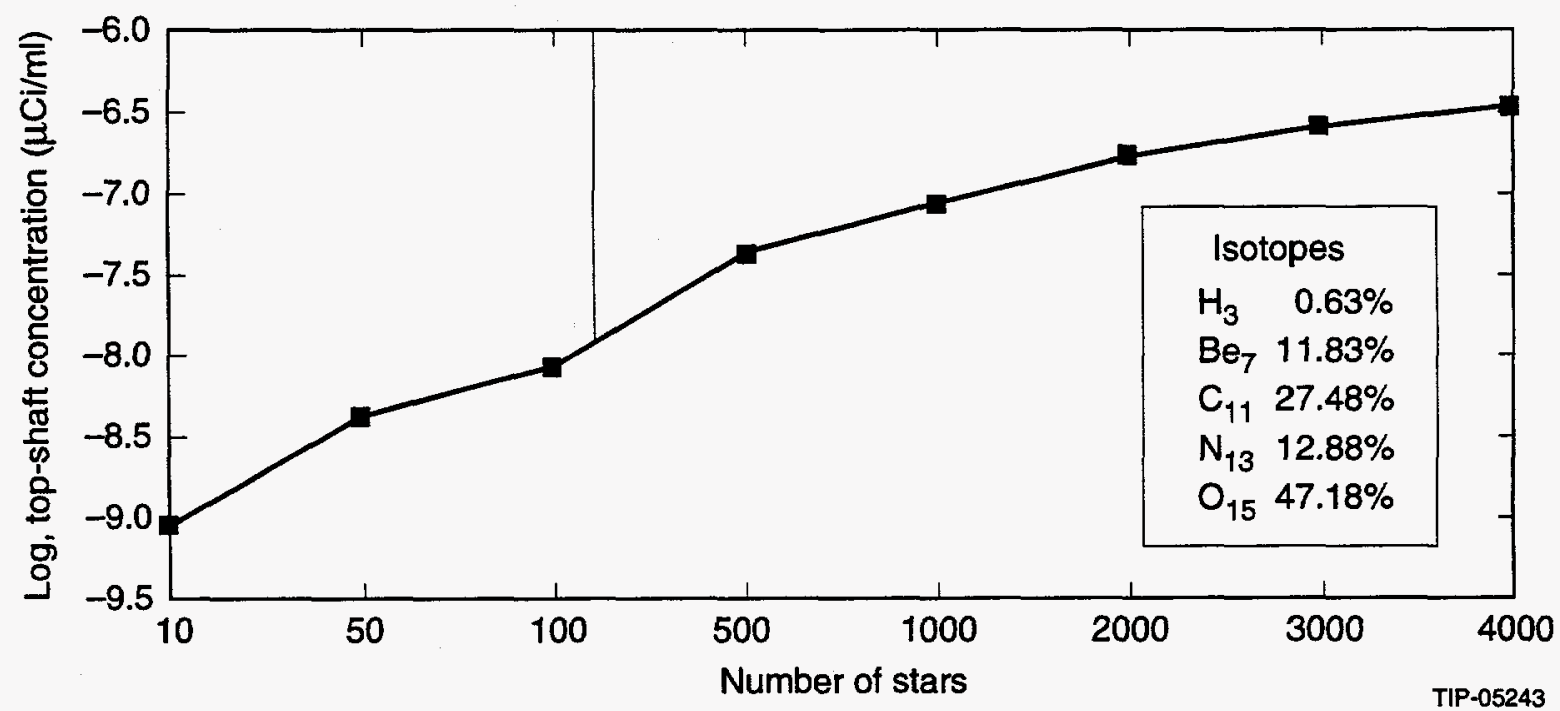

Figure 10. Variation of isotope concentration in $\mathrm{H}_{2} \mathrm{O}$-contamination as a function of the number of stars per hadron.

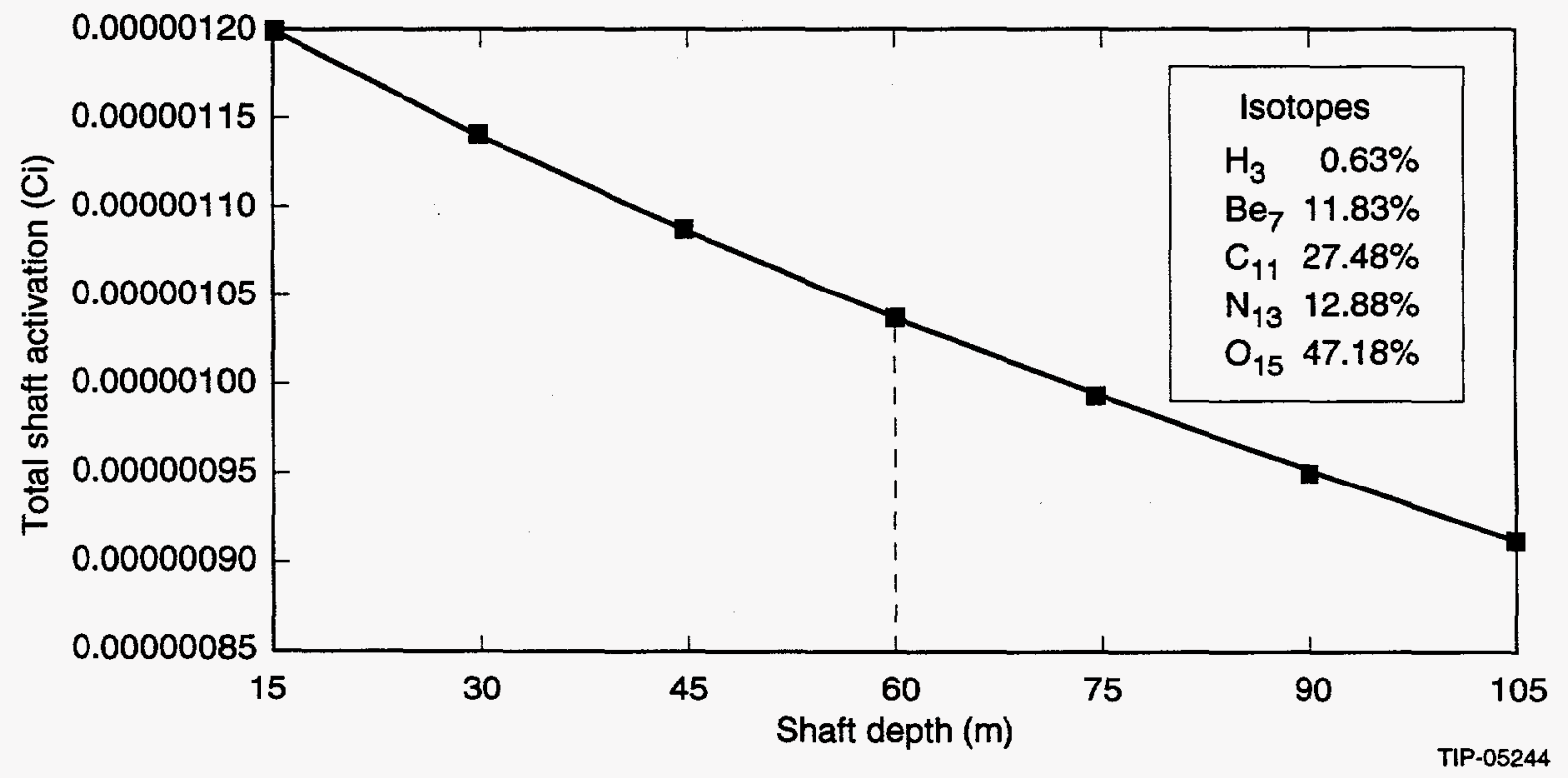

Figure 11. Activation in $\mathrm{H}_{2} \mathrm{O}$-contamination as a function of shaft depth. 
(a)

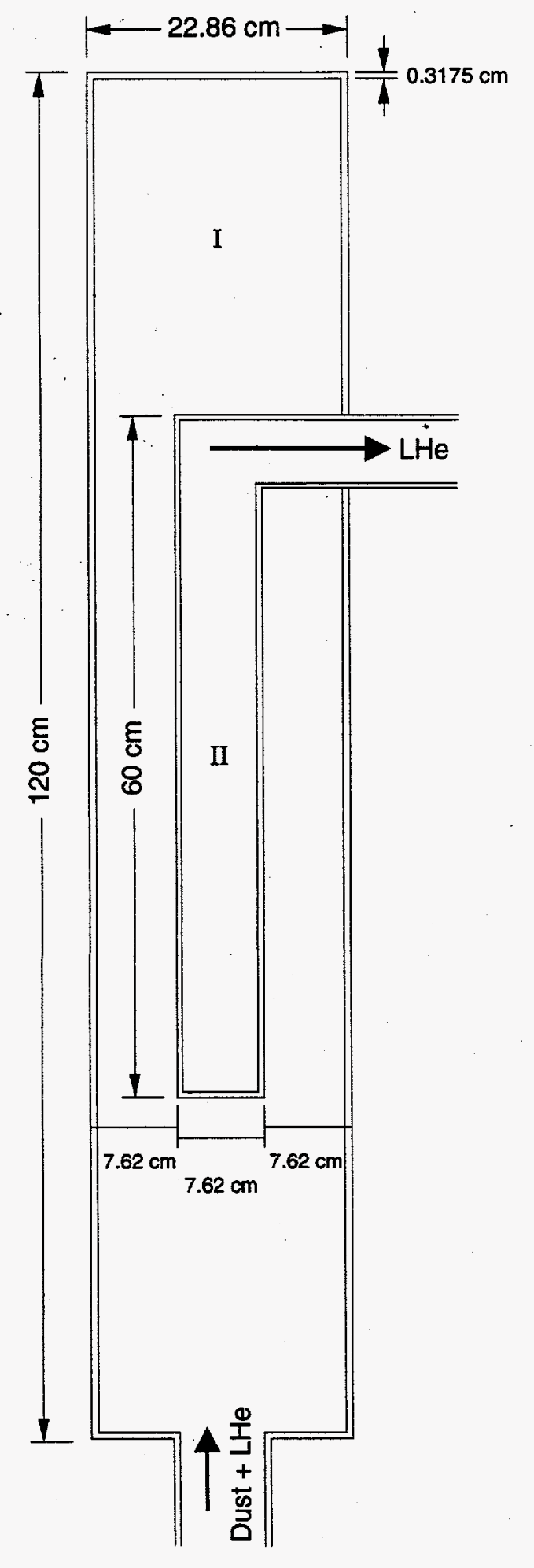

(b)

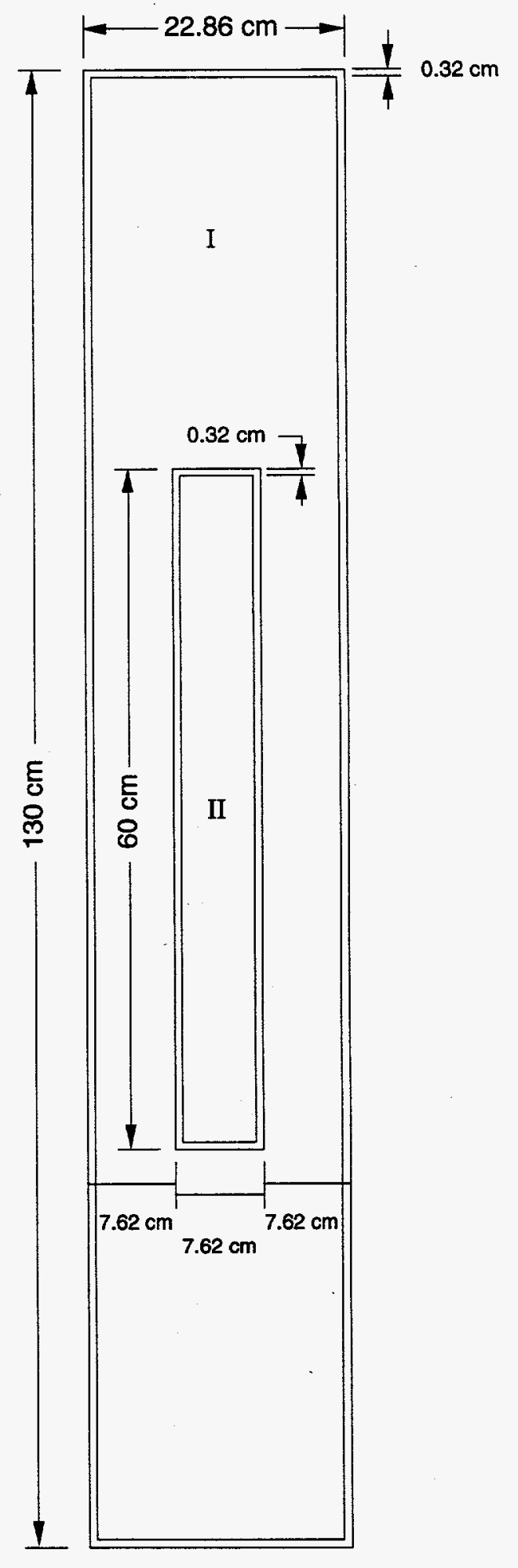

TIP-05245

Figure 12. (a) Stainless steel LHe filter; (b) Filter model to be used for practical calculations. 